\title{
Central de material e esterilização na formação do Enfermeiro: proposta de um Manual de Práticas
}

\section{Material and sterilization central in nursing education: proposal for a practical guide}

\author{
${ }^{1}$ Clarice Mayremi Toshimitu Hoyashi \\ ${ }^{2}$ Denise Celeste Godoy de Andrade Rodrigues \\ ${ }^{3}$ Maria de Fátima Alves de Oliveira
}

\section{RESUMO}

O reprocessamento de materiais tem sido atualmente um grande desafio para a equipe de enfermagem, pois a diversidade de tipos, composições e formas dificultam a realização do processo de desinfecção e esterilização de artigos hospitalares. Este estudo tem como fim produzir um Manual Prático para Enfermagem em Central de Material e Esterilização (CME) a ser utilizado como instrumento de apoio didático na graduação de enfermagem e na formação continuada de enfermeiros. Os objetivos específicos traçados foram: identificar as concepções prévias sobre a CME, descrever as dificuldades encontradas por acadêmicos de enfermagem em associar o ensino teórico com a prática, identificar instrumentos do ensino teórico-prático que possam auxiliar os sujeitos da pesquisa e levantar temas relevantes para a elaboração de um manual de prática para o ensino acadêmico. $\mathrm{O}$ método utilizado foi o descritivo de caráter qualitativo e a pesquisa de campo foi aplicada aos acadêmicos do $6^{\circ}$ período de enfermagem. Os resultados apontaram que embora eles tivessem algum conhecimento prévio sobre a CME, identificaram certo grau de dificuldade na aprendizagem. Nesse sentido, acredita-se que a utilização de um manual prático da CME, poderá contribuir para o ensino e estimular debates entre alunos e professores confrontando a teoria ao exercício da prática, o que poderá possibilitar uma análise crítica dos problemas atuais.

Palavras-chave: enfermagem; central de material e esterilização; manual didático; ensino.

\section{ABSTRACT}

The reprocessing of materials has been nowadays a great challenge for the nursering team, because the diversity of kinds, compositions and shapes make difficult the performance of desinfection process and hospital articles sterilization. This study has as purpose produce a nursering practice manual in material sterilization center (MEC) to be used as didatic support tool in nursering graduation. The specific goals traced were identifying the previous conceptions about MEC, describing the difficulties found by nursering students in associating theorical teaching with practice, identifying tools from the theorical practical teaching that can help the research subjects and consider important themes to elaboration of a practical manual for academical teaching. The method used was the descriptive one with quanti-qualitative feature and the field research was applied to academical students of the sixth period of nursering, where the results pointed that although they had some previous knowledge about CME they identified a certain grade of difficulty in learning. In this sense, it is believed that the use of a practical CME manual, may contribute to teaching and stimulate discussion among students and teachers confronting the theory to the exercise of the practice, which may enable a critical analysis of current problems.

Keywords: nursering; material and sterilization center; didatic material; teaching.

1 Centro Universitário de Volta Redonda - UniFOA. clarice.hoyashi@hotmail.com

2 Centro Universitário de Volta Redonda - UniFOA; Universidade do Estado do Rio de Janeiro - UERJ. denise.cgar@gmail.com

3 Centro Universitário de Volta Redonda - UniFOA; IOC/FIOCRUZ. bio alves@yahoo.com.br 


\section{INTRODUÇÃO}

A enfermagem tem se dedicado ao longo de sua história a cuidar de pessoas. $\mathrm{O}$ atendimento prestado pela equipe de enfermagem, abrange em uma visão holística, um olhar completo e profundo em torno da assistência. Assim, pode-se dizer que o cuidado pode ser dividido em dois, o primeiro é o cuidado direto, realizado com procedimentos técnicos e semiológicos, tais como administração de medicamentos, higiene, conforto, exame físico e outros. O segundo é o cuidado indireto, atribuído ao preparo de materiais e equipamentos em condições de uso seguro no paciente.

Dada a importância do exercício da enfermagem no contexto geral da saúde, pode-se entender o papel do ensino na qualificação profissional. Existem duas categorias profissionais na enfermagem que atuam na prática: o enfermeiro cuja formação é universitária e o técnico de enfermagem, com formação do ensino médio profissionalizante. Ambas são essenciais para o desenvolvimento de habilidades técnicas específicas, baseado no conhecimento científico.

Compete ao enfermeiro o gerenciamento em diversas unidades de trabalho no hospital, dentre essas, o setor Central de Material e Esterilização (CME). A CME é o local onde se recebe a maioria dos materiais usados na assistência médica, odontológica, fisioterápico e de enfermagem, cujo sua finalidade é submeter materiais ao processo de esterilização e desinfecção de forma padronizada, ofertando artigos livres de contaminação e seguros para serem utilizados na assistência da equipe de saúde.

O enfermeiro é o responsável técnico pela operacionalização das etapas que constituem o reprocessamento de materiais na CME. Controla e supervisiona a equipe de enfermagem que desempenha atividades de recebimento, limpeza, preparo, esterilização/desinfecção, armazenamento e distribuição de materiais para todas as unidades do hospital.

A temática é transversal à vários profissionais da saúde que lidam com materiais, tornando-a significativa para o controle das infecções. Nos serviços de enfermagem, a preocupação se estende desde o preparo até a questão do uso desses materiais no paciente, não importando que profissionais as utilizem, devem estar sempre prontos para o uso.

A formação acadêmica de enfermagem através de um ensino teórico e prático inovador deverá ser capaz de formar enfermeiros preparados para atuar na prática, dando condições a esses futuros profissionais de administrar a CME, desempenhando a função com responsabilidade e competência, baseados em conhecimentos adquiridos durante a graduação sobre o processo de esterilização, adequando-os aos métodos específicos a cada necessidade do material.

A problemática levantada para este estudo é que acadêmicos de enfermagem apresentam dificuldades em associar o ensino teórico à prática da Central de Material e Esterilização na disciplina de Atenção à Saúde do Adulto II. Esta disciplina tem um conteúdo programático que integra o funcionamento da CME, Centro Cirúrgico e assistência de enfermagem cirúrgica.

O fato desta disciplina associar enfermagem em CME ao Centro Cirúrgico, é justificada pela prática em hospitais, onde em muitas instituições, ainda vemos os setores compartilhando o mesmo espaço físico com um único enfermeiro gerenciando as unidades, embora com produtos distintos. A cultura de associar as duas unidades hospitalares, vem desde 1950, considerando o fato que o Centro Cirúrgico é um dos maiores clientes da CME, em relação a demanda de materiais cirúrgicos para a esterilização e a proximidade entre elas diminui, não só o tempo de transporte, como a contaminação dos materiais. Ainda hoje, encontramos uma grande demanda de materiais para a CME, mas vários gestores já reconheceram a necessidade de separação das duas unidades, considerando finalidades distintas, tendo o processo de trabalho gerenciado por enfermeiros em cada setor. 
Avaliando enquanto docente, a compreensão do conteúdo da disciplina Atenção à Saúde do Adulto II e a prática hospitalar, observou-se que alguns alunos da graduação de enfermagem apresentam dificuldades no entendimento da temática. Criar um instrumento didático para facilitar a compreensão da prática poderia melhorar o desempenho desses alunos no campo de atuação? Para responder a este questionamento, elegeu-se como objeto de estudo o ensino de enfermagem na CME, tendo como fim a produção de um manual voltado para prática de procedimentos técnicos e administrativos do enfermeiro na CME.

Diante do exposto, traçamos como objetivo geral produzir um manual para acadêmicos de enfermagem, que possa auxiliá-los na prática dos procedimentos da CME, como instrumento de apoio didático na graduação de enfermagem. Sendo estabelecidos como objetivos específicos: identificar as concepções prévias sobre a CME, descrever as dificuldades encontradas por acadêmicos de enfermagem em associar o ensino teórico com a prática; levantar temas relevantes para a elaboração de um manual de prática para o ensino acadêmico.

\section{FUNDAMENTAÇÃO TEÓRICA}

A essência do ensino nas universidades não visa apenas o ensino-aprendizagem, cuja formação esteja voltada somente para o exercício profissional, mas que a prática seja fundamentada pela teoria. Com base no exposto, o ensino deve retratar experiências práticas do cotidiano profissional dos docentes, aliada a literatura e preparar alunos para o gerenciamento de pessoas no ambiente de trabalho, habilidade nas relações interpessoais, assim como o desenvolvimento de habilidades técnicas específicas.

Na visão de Teixeira et al., (2006) o aprender a fazer oportuniza o desenvolvimento de competências para o enfrentamento dos desafios do mundo do trabalho e está relacionado à competência que possibilita ao profissional trabalhar coletivamente e adquirir qualidades para as relações interpessoais no trabalho, em detrimento da pura qualificação profissional.

Para Reibnitz; Prado (2006), as diretrizes estabelecidas pela Lei de Diretrizes e Bases da Educação (LDB), NISKIER, 1996) apontam para a necessidade de uma postura inovadora, pois o que a escola quer, e seria interessante enquanto profissionais de Enfermagem, é formar um profissional crítico-criativo, consciente de sua responsabilidade ética, política e profissional. Ainda com enfoque no ensino da saúde, é importante ressaltar que futuros profissionais devem estabelecer uma relação entre as informações obtidas e apreendidas na graduação e serem capazes de aplicá-las em ações na prática.

Pinheiro et al., (2006) enfatizaram que o conhecimento deve receber tratamento multidirecional, permitindo a compreensão complexa da realidade, a circulação de diferentes valores (interesses ou ponto de vista) presentes nas questões humanas, científicas e sociais. Deve haver uma relação mais estreita entre os conteúdos que são trabalhados no currículo e as necessidades dos estudantes, de maneira que possam ser utilizados em diferentes contextos e situações profissionais cotidianas.

Graças à evolução tecnológica, muitos indivíduos que no passado evoluíam à óbito, atualmente possuem boa expectativa de vida, muitas vezes sem sequelas. Uma vez que a tecnologia é como um conjunto de saberes e fazeres relacionados com produtos e materiais que definem terapêuticas e processo de trabalho que constituem instrumentos ou extensões de nossa habilidade física e mental de realizar ações (RODRIGUES et al., 2008; ARONE e PHILIPPI, 2009).

O progresso da ciência e da tecnologia sistematicamente vem trazendo benefício à saúde do homem. Equipamentos tornaram-se mais precisos em cada área especifica, tornando possível a identificação diagnóstica mais rápida, avaliação do estágio da doença, permitindo a intervenção no tratamento, afim de promover a recuperação do indivíduo em menor tempo possível, evitando possíveis complicações. 
Baseado nessa realidade, Silva et al., (2009) explicam, que a educação em enfermagem tem sentido a necessidade de mudanças, visto que, o aluno da atualidade participa como sujeito na construção de conhecimentos e não mais como somente um espectador. Criar novas estratégias de ensino, mais criativa e inovadora afim de incentivar/motivar o aluno é uma possibilidade que o profissional da área deve buscar.

Para Aguiar et al., (2009) durante a formação dos profissionais de enfermagem há necessidade de compreender de forma ampliada o processo de cuidar, de maneira a ser possível uma renovação da dinâmica administrativa dos serviços de enfermagem. A valorização do conhecimento específico do enfermeiro no CME é um reflexo da excelência na qualidade da assistência prestada. $\mathrm{O}$ aluno de graduação em enfermagem tem um grande desafio a ser enfrentado, além de aprender a cuidar de pessoas, também deve aprender a administrar serviços, e nenhum desses papéis pode ser mais relevante que o outro, mas deve estar inter-relacionado para um objetivo comum, a recuperação e o bem-estar do indivíduo.

O despertar da necessidade de qualificação dos serviços na CME, volta-se para o gerenciamento dessa unidade de trabalho (POTTER; PERRY, 2005). Colocar um profissional de saúde capacitado, com conhecimento técnico específico para planejar, coordenar e controlar todo o processo de trabalho na área operacional, é atribuição do enfermeiro, que desde os primórdios do surgimento da profissão é dado a ele a condição de promover o cuidado dos pacientes, promovendo também o cuidado com os materiais e a organização do ambiente terapêutico (RODRIGUES et al., 2008; MOURA, 2009). Portanto, a chefia da CME deve ser delegada a um enfermeiro, conforme a regulamentação - Lei n ${ }^{\circ} 7.498 / 1986$ pelo Decreto-Lei no $94.406 / 1987$, que dispõe sobre o exercício da enfermagem e dá outras providências. No que se refere a responsabilidade no preparo de materiais e equipamentos hospitalares para o uso, este é um dos papéis fundamentais da equipe de enfermagem.

Nesse contexto, o profissional de enfermagem deve se manter em aprimoramento contínuo, devido à velocidade com que a tecnologia se desenvolve e aos desafios e expectativas da sociedade e das instituições com relação ao seu trabalho (MATTOS e STIPP, 2009).

\section{MÉTODOS E TÉCNICAS}

O método utilizado para o estudo foi de caráter descritivo e com abordagem qualitativa. O cenário de estudo foi o Centro Universitário de Volta Redonda - UniFOA, localizado no município de Volta Redonda, R.J.

O curso inserido no estudo foi o de graduação em Enfermagem e a disciplina envolvida Atenção à Saúde do Adulto II, por ser nessa disciplina, o desenvolvimento do tema Central de Material e Esterilização.

O projeto de pesquisa foi encaminhado ao Comitê de Ética em Pesquisa em Seres Humanos (CoEPS) do Centro Universitário de Volta Redonda - UniFOA, processo nº 184/09, protocolo Fundação Oswaldo Aranha nº 063323.

Os instrumentos de coleta de dados foram dois questionários. O primeiro questionário contendo duas perguntas abertas, e o segundo questionário contendo duas perguntas abertas e uma fechada, que foram aplicados aos alunos no início e ao término, da disciplina Atenção à Saúde do Adulto II.

\section{DESENVOLVIMENTO}

A intenção do instrumento aplicado antes da disciplina Atenção à Saúde Adulto II, foi levantar o conhecimento prévio do aluno sobre a atuação do enfermeiro na CME, cuja temática é abordada. No segundo momento de aplicação do questionário, buscou-se através dos registros dos depoentes, analisar o nível de conhecimento adquirido durante as aulas expositivas. Portanto não há correlação entre o primeiro e o segundo questionário aplicado, ou seja, nenhum dado comparativo entre os dois questionários. 
Participaram da pesquisa respondendo ao primeiro questionário, 66 acadêmicos e respondendo ao segundo questionário foram 80 acadêmicos do $6^{\circ}$ período de graduação de Enfermagem das turmas vespertino e noturno. Foram excluídos do estudo, alunos de dependência na disciplina de Atenção à Saúde do Adulto II e alunos transferidos após a aplicação do primeiro questionário de avaliação.

Com relação à análise dos dados, cada resposta foi analisada individualmente e ao mesmo tempo, sendo agrupadas por descrições similares. Os agrupamentos de respostas formaram em cada pergunta, categorias. Ao término da análise dos resultados, foi possível delinear o conteúdo do produto elaborado, o manual de procedimentos da CME.

\section{RESULTADOS E DISCUSSÃO}

Em relação ao primeiro questionário aplicado, composto de duas perguntas, foram respondidos por 66 (100\%) alunos.

A primeira pergunta referiu-se ao entendimento de acadêmicos de enfermagem sobre a finalidade da CME em uma instituição de saúde. Os agrupamentos formados pelas respostas similares resultaram nas seguintes categorias de respostas: 1) Procedimentos técnicos de esterilização e desinfecção de artigos hospitalares e 2) Prevenção e controle de infecção relacionado ao material reutilizável.

Na categoria Procedimentos técnicos de esterilização e desinfecção de artigos hospitalares, os resultados mostraram que 37 (56,1\%) depoentes revelaram possuir um bom conhecimento prévio sobre a CME, mesmo que não tenham tido a disciplina de Saúde Adulto II, no $6^{\circ}$ período. Esses depoentes apontaram a CME como o setor responsável pela esterilização e desinfecção de artigos hospitalares.

O processo de esterilização de artigos hospitalares foi a resposta descrita por 30 depoentes como sendo a atividade principal da CME, talvez, relacionando a identificação do setor com a função executada por seus integrantes no setor em questão.

Entretanto, do quantitativo de 37 depoentes, 7 acadêmicos descreveram a desinfecção e esterilização de artigos hospitalares como a principal atividade que envolve a CME. As respostas identificam certo detalhamento do reprocessamento de materiais, visto que, na CME são realizados simultaneamente os dois procedimentos.

Entender que a CME é o local adequado para o reprocessamento de artigos hospitalares, no qual abrange métodos apropriados de esterilização e desinfecção, faz pensar que os artigos hospitalares deverão ser classificados quanto a condição de uso, considerando a composição do material e a finalidade do procedimento. Essa relação é necessária para o encaminhamento correto do método a ser empregado.

Guadagnin et al., (2005) enfatizaram que hoje a tendência é que esta unidade, principalmente nos hospitais de grande e médio porte, seja independente e autônoma, com a finalidade de apoiar todos os setores que prestam atendimento diagnóstico e terapêutico aos pacientes. Desta forma, garante que todas as etapas do reprocessamento dos artigos (limpeza, secagem, preparo, acondicionamento, desinfecção e/ou esterilização, armazenamento e distribuição) sejam cumpridas, passando por processos padronizados e controlados.

Em relação à categoria Prevenção e controle de infeç̧ão relacionado ao material reutilizável, 26(39,4\%) relacionaram a finalidade da CME com os materiais contaminados e o controle de infecção hospitalar, revelando de certa forma uma compreensão indireta e não ideal concisa sobre a CME.

Associar limpeza e descontaminação dos materiais usados na assistência de enfermagem está relacionada ao controle da infecção hospitalar, visto que, o material é um dos veículos de maior acesso ao cuidado de pacien- 
tes hospitalizados. A falha ocorrida em um dos processos que segue a recomendação dos métodos de esterilização pode induzir o paciente a infecção.

Tipple et al. (2005) citaram que para compreender a contextualização do CME no processo de controle de infecção, basta atentar-se ao fato da utilização dos artigos odonto-médico-hospitalares sem o devido comprometimento dos serviços prestados ao cliente. É necessário que tais artigos tenham previamente passado por um fluxograma unidirecional que se resume em limpeza, secagem, preparo e esterilização e estocagem. Qualquer falha ocorrida durante o processamento implica em possíveis complicações como, por exemplo, infecção trans ou pós-operatória.

Para o encerramento da primeira pergunta, constatou-se que somente 3(4,5\%) alunos não souberam emitir nenhum conceito ou relacionar situações que pudessem dar algum entendimento à CME. Esses alunos alegam não pertencer a área de saúde, portanto não tem qualquer noção sobre a CME.

Quanto à segunda pergunta, buscou-se levantar através da descrição das respostas dos questionários, se acadêmicos de enfermagem conhecem o papel do enfermeiro na CME, embora ainda não tenham sido discutidos sobre a temática na disciplina de Saúde Adulto II.

Ao analisar as respostas de 66 (100\%) alunos que responderam o primeiro questionário, os resultados apontaram três categorias de respostas. 1) Gerenciamento de ações na CME, 2) Perfil do enfermeiro na CME e 3) Desconhecimento sobre o papel do enfermeiro da CME.

Em relação ao Gerenciamento de Ações de Enfermagem, evidenciou-se que 56 (84,8\%) alunos conseguiram descrever algum dos papéis do enfermeiro na CME. Nota-se nas entrelinhas detalhamento das atividades realizados no setor, o que pode tornar-se fácil a compreensão do aluno com a exposição da temática.

A concepção teórica prévia do aluno, no contexto desta temática, poderá contribuir para agregar ou assimilar melhor o conteúdo sobre o funcionamento da CME e seu futuro desempenho como líder de equipe frente as situações de coordenação e gerenciamento de ações na CME.

Para Aguiar et al., (2009) o enfermeiro é um administrador que precisa preocupar-se com a questão gerencial de recursos materiais e humanos adequando à realidade institucional sem, contudo, esquecer da importância da adoção de medidas dinâmicas e planejadas na organização do trabalho. Para tanto se faz necessário que os enfermeiros, que atuam em CME, desenvolvam formas de qualificar suas práticas frente às crescentes apresentações de produtos usados na assistência, que estabelecem novos modos de produção e novas relações de trabalho.

A atualização profissional é um constante desafio para o enfermeiro, pois ele será o multiplicador de ações no setor onde atua, mantendo sua equipe preparada no atendimento aos clientes. É fundamental ao professor estar constantemente atualizado e estimular acadêmicos na busca de novos conhecimentos que possam utilizar em práticas futuras.

Quanto ao Perfil do Enfermeiro na CME, 5(7,6\%) dos alunos responderam como o enfermeiro da CME deve se comportar diante do processo de trabalho nesse setor, o que caracteriza o perfil profissional. Vale enfatizar que o perfil está associado ao papel do enfermeiro.

Embora tenha sido um pequeno grupo de acadêmicos a identificar o perfil desejado do enfermeiro na CME, é algo bastante significativo se associado à competência desse profissional exercida no setor. Compartilhando do mesmo pensamento Possari (2008) citou as características que um enfermeiro deve possuir. São elas: exercer liderança perante o grupo, ter pensamento estratégico com capacidade de decisão e solução de problemas, ter uma visão crítica da realidade sócio-político-econômica do país para uma participação efetiva no siste- 
ma de saúde, gerenciar ações de enfermagem no âmbito da saúde, buscar sua constante capacitação e atualização e atuar como membro educador desenvolvendo processos e tecnologias nos serviços de saúde e comunidade.

Na categoria Desconhecimento sobre o papel do enfermeiro da CME, apesar de a maioria ter bom entendimento sobre o papel do enfermeiro na CME, às vezes confundidos ao perfil, pode-se identificar ainda que, infelizmente, alguns acadêmicos de enfermagem 5(7,6\%) desconhecem a temática por falta de vivência na área da saúde.

O trabalho, como princípio educativo, não pode ser uma mera aprendizagem formal, teórica ou intelectualizada (GRINSPUN, 2010). Há de ser uma reflexão orientada por professores e especialistas com base na experiência vivida pelos alunos no trabalho desenvolvido dentro e fora da escola. Grande parte de nossos alunos das classes populares já ingressou no trabalho, portanto, não o desconhece.

Dessa maneira, é possível entender que aqueles alunos que trabalham ou trabalharam na área de saúde, especificamente em hospitais, possuem concepções que podem favorecer o seu aprendizado. De acordo com Teixeira et al., (2006) o conhecimento consiste em representações da realidade, constituídas no decorrer das experiências vividas e no processo de formação.

O segundo questionário foi aplicado aos 80(100\%) acadêmicos de enfermagem da mesma turma, que participaram do primeiro questionário, após a administração das aulas teóricas e práticas em laboratório de habilidades, usando os recursos que a universidade oferece.

Com base na primeira pergunta, referente à descrição de dificuldades relacionadas por acadêmicos de enfermagem em associar o ensino teórico à prática, emergiram as seguintes categorias de respostas: 1) Aulas práticas insuficientes para o conteúdo e 2) Dificuldade em relacionar procedimentos técnicos à prática.

Na categoria Aulas práticas insuficientes para o conteúdo, 48(60\%) de depoentes demonstraram dificuldades em assimilar o conteúdo da temática com a quantidade de aulas práticas, pois atribuem às aulas práticas, a possibilidade de melhorar o entendimento teórico da disciplina. O entendimento que se tem, a partir da análise dos depoentes é que deve existir uma interseção da prática fundamentada na teoria aplicada, entretanto, para haver essa fusão, no qual se concretiza o ensino e a aprendizagem, são necessários recursos como materiais e equipamentos e a quantidade de aulas práticas que possam aproximar o aluno da realidade. Para Teixeira et al., (2006) as aulas práticas precisam ser desenvolvidas em espaços adequados ao número de estudantes, ter material de consumo suficiente e ainda equipamentos disponíveis para uso e/ ou demonstração.

Para a categoria de resposta Dificuldade em relacionar procedimentos técnicos à prática, 28(35\%) dos depoentes descreveram que a dificuldade na aprendizagem se identifica em procedimentos técnicos relacionados ao manuseio de equipamentos existentes na CME e materiais diversos. Pinheiro et al., (2006) conferiram às ações da prática, uma ferramenta de assimilação e descreveram que analisar experiências, significa conceber o cotidiano como o lugar onde as ações desenvolvidas, sejam elas simbólicas ou práticas, produzem sentidos e se configuram como práxis. A preocupação acadêmica é significativa, se considerar que a CME, é um setor exclusivamente operacional e complexo no sentido de que todos os procedimentos técnicos estão associados ao funcionamento de materiais e equipamentos hospitalares. Contudo, a aprendizagem será gradativa quando o aluno tiver contato regularmente com o ambiente cirúrgico e a CME.

Neste aspecto, embora entendendo as dificuldades encontradas para assimilar todo o conteúdo necessário do processo de trabalho da CME, Rosa (2009), persistiu em afirmar que, a CME deve ser administrado por profissional responsável e competente para exigir uma qualidade de atendimento necessário à instituição com conhecimento profundo das técnicas de esterilização, manejo dos equipamentos e diferentes instrumentais cirúrgicos. 
Caberia então uma reflexão: que estratégia de ensino poderia minimizar as dificuldades encontradas por alunos em associar teoria à prática? Talvez um manual de práticas bem fundamentado e simplificado poderia facilitar o entendimento desses acadêmicos.

É importante citar ainda que, na primeira pergunta do segundo questionário aplicado, dos 80(100\%) dos depoentes que responderam sobre as dificuldades encontradas em associar o ensino teórico à prática na CME, há de considerar que 4(5\%) de depoentes não revelaram qualquer dificuldade na aprendizagem sobre a temática.

Felizmente, embora citado por poucos alunos, as aulas expositivas foram satisfatórias, pois houve a apreensão do conhecimento pelo aluno, apesar do conteúdo extenso. Esse é o nosso maior desafio enquanto professor, tornando-se gratificante quando o objetivo é alcançado. Segundo Freire (2010), quando o professor possui experiência na execução da prática, conhecendo as diferentes dimensões que a caracterizam, o professor torna-se mais seguro para desempenhar seu papel enquanto educador.

Para finalizar as questões referidas ao segundo questionário, a última pergunta, diz respeito ao conteúdo do manual proposto como produto desse estudo científico. A interação de acadêmicos de enfermagem que assistiram as aulas teórico-práticas da disciplina de Atenção à Saúde do Adulto II elegeu conteúdos para a confeção do manual da temática CME, mostrado em termos percentuais na Figura 1.

A participação de acadêmicos de enfermagem na elaboração do próprio manual poderá contribuir para o direcionamento de um conteúdo mais consistente e claro para o seu entendimento. A interação de aluno no processo educativo poderá torná-lo mais proativo na busca de seus ideais, tornando-o mais crítico em comparação com a realidade.

Figura 1 - Conteúdo do Manual de Prática da CME, apontados na pesquisa.

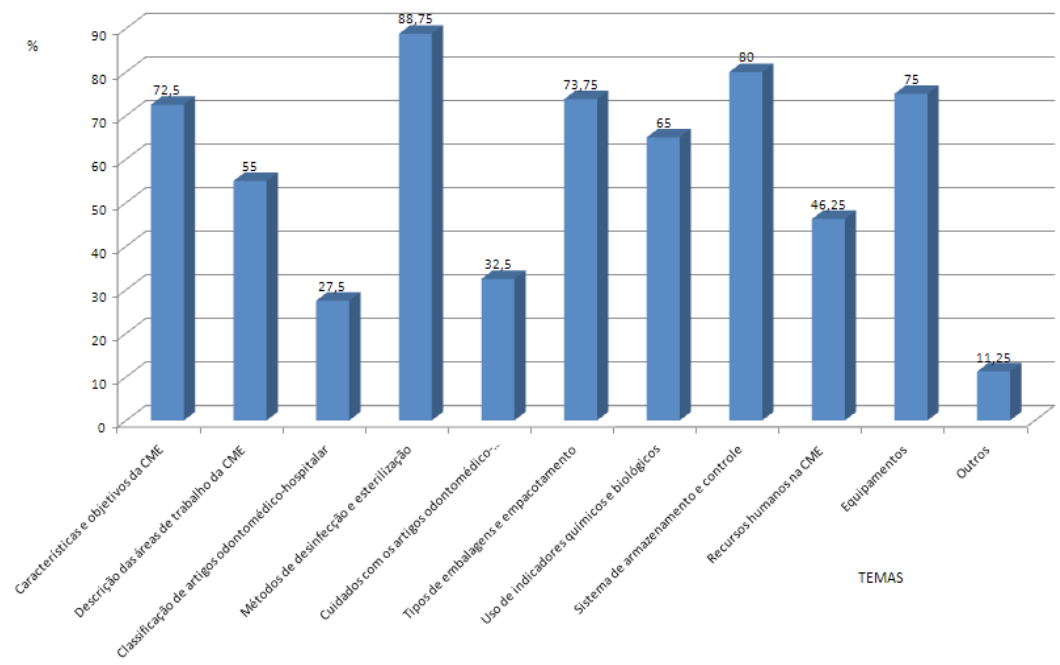

Fonte: Os autores.

\section{CONSIDERAÇÕES SOBRE O PRODUTO EDUCACIONAL}

Afim de auxiliar os acadêmicos de enfermagem no processo ensino-aprendizagem, optou-se como produto desse mestrado, por um manual de prática. Este instrumento foi idealizado por se tratar de um material de fácil manuseio, possibilitando ao aluno carregá-lo em locais de sua atuação, tanto em aulas práticas de laboratório quanto em hospitais, sendo possível realizar discussões mediante as fundamentações teóricas do instrumento com a realidade do momento. 
Echer (2005) recomendou dispor um material educativo e instrutivo que facilite e uniformize as orientações a serem realizadas, com vistas ao cuidado em saúde. É importante lembrar que o conhecimento científico se renova constantemente e assim, há necessidade de atualização permanente do material instrucional para que ele alcance seus objetivos.

As vantagens oferecidas por um manual, uma apostila ou uma cartilha é a portabilidade, pois é possível levá-lo a qualquer lugar onde houver a necessidade de consulta. Sendo o conteúdo mais objetivo e voltado para a praticidade das ações, pode acompanhar o acadêmico durante a prática em laboratório ou em campo da prática hospitalar.

O manual constitui-se em um material educativo, contendo 100 páginas. Estas têm a dimensão de 24x18 mm, impressas na cor preta, azul, contendo fotos coloridas, presas por espiral, cuja capa é mostrada na Figura 2. O manual foi denominado "Manual de Práticas para Enfermagem - Central de Material e Esterilização”.

A idealização do Manual de Práticas em Central de Material e Esterilização teve como princípio a descrição de pontos significativos da operacionalização da prática com a descrição de textos simples e de fácil compreensão. O bom entendimento de acadêmicos e profissionais de enfermagem pode proporcionar melhorias da qualidade técnica na execução de atividades no cotidiano nesse setor.

Procurou-se neste manual ofertar não só as bases para a formação dos alunos, mas um instrumento didático útil e atualizado para todos os profissionais. O manual apresenta inicialmente, nos dois primeiros capítulos, a finalidade e os objetivos de uma CME, localizando não só a área física necessária para a realização de um trabalho com qualidade, como também situando os profissionais de enfermagem nesse contexto.

Figura 2 - Capa do Manual

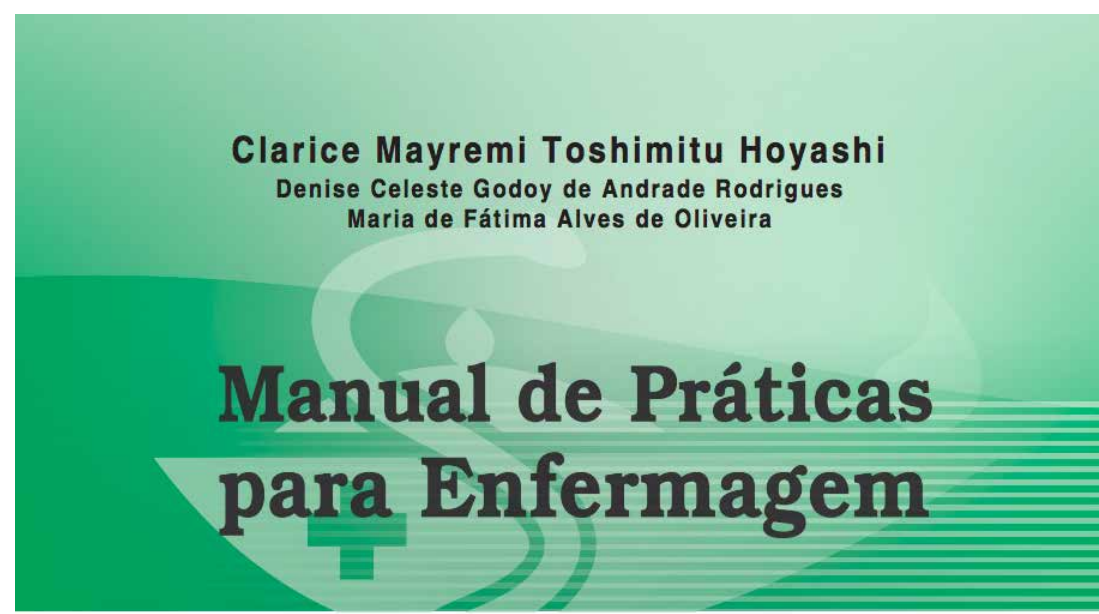

CENTRALDE MATERIALE ESTERILIZAÇÃo (CME)

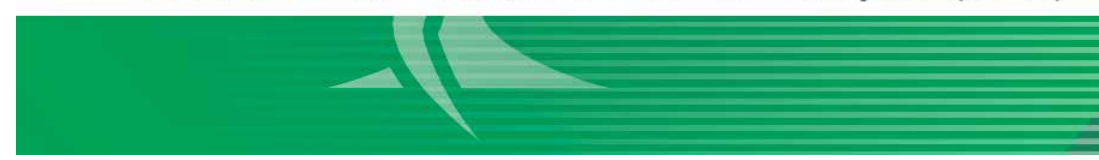

Fonte: Os autores.

No terceiro capítulo, apresenta-se a classificação de artigos odonto-médico-hospitalar. O conteúdo do quarto e do quinto capítulos versa sobre métodos de desinfecção e esterilização, identificando vantagens e desvantagens inerentes a cada um. No sexto capítulo, mostram-se todas as etapas do reprocessamento de materiais na CME com a exposição de figuras ilustrativas, que podem contribuir para compreensão dos textos escritos. No sétimo capítulo, é enfatizada a importância da realização do empacotamento de materiais em embalagens que sejam adequadas aos métodos de esterilização, garantindo não somente a permeabilidade do agente esteri- 
lizante, mas para obter a barreira eficaz, evitando a recontaminação dos materiais. Seguindo o oitavo capítulo com a apresentação dos testes padronizados pelo Ministério da Saúde, no que se refere à garantia da qualidade da esterilização nos vários métodos.

E finalmente, o último capítulo aponta sucintamente alguns cuidados especiais com os instrumentos cirúrgicos e seu controle nas etapas do processo na CME.

\section{CONCLUSÃO}

A infecção hospitalar é um problema que preocupa a equipe interdisciplinar de saúde, apesar de todo o tratamento a que se destina o paciente ser correto, há riscos de complicações. Nesse sentido, a enfermagem busca constante aperfeiçoamento dos procedimentos técnicos no manuseio de equipamentos e materiais que surgem no mercado da saúde hospitalar.

A responsabilidade do enfermeiro envolve toda a assistência prestada ao paciente, direta ou indiretamente. $\mathrm{O}$ cuidado com materiais e equipamentos são cuidados indiretos que influenciam na assistência da equipe de saúde, dependendo do seu reprocessamento.

A CME é o local apropriado para o processamento de materiais, a eficácia no processo de esterilização e/ou desinfecção dos artigos hospitalares depende de um conjunto de medidas como estrutura física adequada, equipe capacitada, recursos de materiais e equipamentos próprios para a operacionalização em todas as etapas do processo.

O enfermeiro deve estar preparado para gerenciar esta unidade, através de conhecimento específico e atualizado, além de ser necessário um perfil para atuar de forma dinâmica, com reconhecido papel de líder de equipe.

Os resultados da pesquisa puderam comprovar que o primeiro questionário identificou que a maioria possuía um bom conhecimento prévio à disciplina, quanto a finalidade e o papel do enfermeiro na CME, mesmo aqueles que nunca atuaram no setor. O segundo questionário aplicado, que ocorreu posteriormente ao conteúdo apresentado em sala de aula e aulas práticas, mostrou que a maioria referiu dificuldades em associar ensino teórico à prática, relacionando-as à pouca carga horária na disciplina dada e dificuldade para assimilar os procedimentos técnicos à prática em campo.

O manual elaborado será utilizado na disciplina de Atenção à Saúde do Adulto II e com o patrocínio de uma empresa de saúde suplementar servirá como ferramenta de trabalho. Além disso, ficará à disposição para consultas de profissionais enfermeiros, orientando o trabalho na CME e áreas afins.

Nesse sentido, acredita-se que a utilização de um manual prático da CME, aqui apresentada, poderá possibilitar discussões entre o professor e o aluno, motivando reflexões sobre a prática. 


\section{REFERÊNCIAS BIBLIOGRÁFICAS}

AGUIAR, BGC; SOARES, E; COSTA DA SILVA; A. Evolução das Centrais de Material e Esterilização: História, Atualidades e Perspectivas para a Enfermagem. Enfermaría Global. Revista Electrônica Cuatrimestral de Enfermeria, n.15, 2009.

ARONE, E. M.; PHILIPPI, M.L.S. Introdução à Enfermagem Médico-cirúrgica. 2. ed. Revisada e Ampliada. São Paulo: Editora Senac São Paulo, 2009. p. 103. 143 p.

ECHER, I.C.. Elaboração de Manuais de Orientação para o Cuidado em Saúde. Rev. Latino-am Enfermagem 2005 setembro-outubro; 13(5):754-7.

FREIRE, P.. Pedagogia da Autonomia - saberes necessários à prática educativa. São Paulo: Paz e Terra, 2010. p.39, 68.148 p.

GRINSPUN, M. P. S. Z.. A Orientação Educacional: Conflito de paradigmas e alternativas para a escola. 4. ed. São Paulo: Cortez, 2010. p. 125. 216 p.

GUADAGNIN, S. V. T.; PRIMO, M. G. B.; TIPPLE, A. C. F. V.; SOUZA, A. C. S.. Centro de Material e Esterilização: Padrões Arquitetônicos e o Processamento de Artigos. Revista Eletrônica de Enfermagem, v.7, n.3, p. 285-293, 2005.

MATTOS, V.Z., STIPP, M.A.C. Programa Trainee: um modelo de gestão de enfermeiras recém-graduadas. Acta Paulista de Enfermagem, v.22, n.6, p.833-835, 2009.

MOURA, M. L. P. A.. Enfermagem em Centro de Material e Esterilização. 9ed. São Paulo: Senac, 2009. p.11,13,15,17,55. 87 p.

NISKIER, Arnaldo. LDB: a nova lei da educação: tudo sobre a lei de diretrizes e bases da educação nacional: uma visão crítica. Rio de Janeiro: Consultor, 1996.

PINHEIRO, R.; CECCIM, R. B.; MATTOS, R. A.. Ensinar Saúde: a integralidade e o SUS nos cursos de graduação na área da saúde. 2ed. Rio de Janeiro: IMS/UERJ - CEPESC - ABRASCO, 2006. p.18, 210. 336 p.

POSSARI, J. F.. Centro Cirúrgico: Planejamento, Organização e Gestão. 3. ed. São Paulo: Iátria, 2008. p. 292. 308 p. POTTER, P. A.; PERRY, A. G.. Fundamentos de Enfermagem. 6. ed. Rio de Janeiro: Elsevier, 2005. Volume I. p. 74-366. 866 p.

REIBNITZ, K. S.; PRADO, M. L. . Inovação e Educação em Enfermagem. Florianópolis: Cidade Futura, 2006. p. 30. 240 p.

RODRIGUES, A. B. et al. O Guia da Enfermagem - Fundamentos para assistência. São Paulo: Iátria, 2008. p. $108,130,131.424$ p.

SILVA, R. M.; SILVA, I. C. M.; RAVAGLIA, R. A.. Ensino de Enfermagem: Reflexões Sobre o Estágio Curricular Supervisionado. Práxis, Ano I, nº 1, Janeiro, p. 38, 2009.

TEIXEIRA, E.; VALE, E.G.; FERNANDES, J. D.; DE SORDI, M. R. L.. O Ensino de Graduação em Enfermagem no Brasil: O Ontem, O Hoje e o Amanhã. Brasília: Instituto Nacional de Estudos e Pesquisas Educacionais Anísio Teixeira, 2006. p.46, 86. 132 p.

TIPPLE, A. F. Veiga; SOUZA, T. R.; BEZERRA, A. L. Q.; MUNARI, D. B.. O trabalhador sem formação em enfermagem atuando em centro de material e esterilização: desafio para o enfermeiro. Revista da Escola de Enfermagem da USP, v.39, n.2, 2005. 